\title{
Withdrawal of dietary phytoestrogens in adult male rats affects hypothalamic regulation of food intake, induces obesity and alters glucose metabolism
}

\author{
María Florencia Andreoli a,b, Cora Stoker a,b, Marría Florencia Rossetti a,b, Ana Alzamendi c,

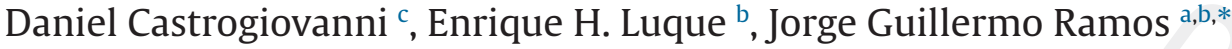 \\ a Departamento de Bioquímica Clínica y Cuantitativa, Facultad de Bioquímica y Ciencias Biológicas, Universidad Nacional del Litoral, Argentina \\ b Laboratorio de Endocrinología y Tumores Hormonodependientes, Facultad de Bioquímica y Ciencias Biológicas, Universidad Nacional del \\ Litoral, Argentina \\ ' Instituto Multidisciplinario de Biología Celular (IMBICE), CONICET-CICPBA, Argentina
}

\section{A R T I C L E I N F O}

\section{Article history:}

Received 27 August 2014

Received in revised form 28 November

2014

Accepted 1 December 2014

Available online

\section{Keywords:}

Phytoestrogens

Obesity

Hypothalamus

Glucose metabolism

\begin{abstract}
A B S T R A C T
The absence of phytoestrogens in the diet during pregnancy has been reported to result in obesity later in adulthood. We investigated whether phytoestrogen withdrawal in adult life could alter the hypothalamic signals that regulate food intake and affect body weight and glucose homeostasis.

Male Wistar rats fed from conception to adulthood with a high phytoestrogen diet were submitted to phytoestrogen withdrawal by feeding a low phytoestrogen diet, or a high phytoestrogen-high fat diet. Withdrawal of dietary phytoestrogens increased body weight, adiposity and energy intake through an orexigenic hypothalamic response characterized by upregulation of AGRP and downregulation of POMC. This was associated with elevated leptin and T4, reduced TSH, testosterone and estradiol, and diminished hypothalamic ER $\alpha$ expression, concomitant with alterations in glucose tolerance.

Removing dietary phytoestrogens caused manifestations of obesity and diabetes that were more pronounced than those induced by the high phytoestrogen-high fat diet intake.
\end{abstract}

(c) 2014 Published by Elsevier Ireland Ltd.

\section{Introduction}

Obesity by definition results from an imbalance between energy intake and energy expenditure; it represents a major threat to the health of populations spanning nearly every country across the globe. It is a chronic, progressive and multifactorial metabolic condition related to numerous diseases that often lead to premature disability and

\footnotetext{
Abbreviations: AgRP, agouti related protein; AUC, area under curve; CART, cocaineamphetamines related transcript; ER, estrogen receptor; HOMA, homeostasis model assessment; HP, high phytoestrogen; HP-HF, high phytoestrogen-high fat; InsR, insulin receptor; ipGTT, intraperitoneal glucose tolerance test; LP, low phytoestrogen; NPY, neuropeptide Y; Ob-Rb, long form of leptin receptor; POMC, proopiomelanocortin.

Declaration of interest: The authors declare that there is no conflict of interest that could be perceived as prejudicing the impartiality of the research reported.

Funding: This work was supported by grants from the Universidad Nacional del Litoral (CAI+D program) and the Argentine National Agency for the Promotion of Science and Technology (ANPCyT). These funding sources had no involvement in study design; collection, analysis and interpretation of data; in the writing of the report; or in the decision to submit the article for publication.

* Corresponding author. Laboratorio de Endocrinología y Tumores Hormonodependientes, School of Biochemistry and Biological Sciences, Casilla de Correo 242, (3000) Santa Fe, Argentina. Tel.: +54 342 4575207; fax: +54 3424575207.

E-mail address: gramos@fbcb.unl.edu.ar (J.G. Ramos).
}

mortality. In particular, it is associated with the development of type 2 diabetes mellitus, coronary heart disease, and hypertension. The etiology of obesity involves numerous factors that can be defined as hereditary, congenital, social and cultural (Kopelman and Grace, 2004; Ogden et al., 2006). There is growing experimental and epidemiological evidence that fetal programming of genetic systems is a contributing factor in the recent global increase in adult obesity (Vom Saal et al., 2012).

The hypothalamus plays a central role in energy homeostasis by regulating both appetite and energy expenditure. The arcuate nucleus in the hypothalamus is the central area involved in the control of food intake (Schwartz et al., 2000; Valassi et al., 2008). It contains two distinct populations of neurons. One contains the orexigenic neuropeptides, such as agouti related protein (AgRP) and neuropeptide Y (NPY). The other population of neurons synthesizes the anorexigenic substances, which consist of cocaine-amphetamines related transcript (CART), and proopiomelanocortin (POMC) (Schwartz et al., 2000; Valassi et al., 2008). These neurons have receptors for ghrelin, leptin, insulin, estrogens, and other circulating hormones. A plethora of interactions between these substances regulates the delicate equilibrium of appetite/satiety. For example, leptin suppresses the activity of neurons that contain NPY and AgRP, and stimulates the activity of neurons that release POMC and CART. This mechanism becomes disrupted in most obese individuals, 
resulting in a state known as central leptin resistance (Mauvais-Jarvis et al., 2013).

Estrogens play a fundamental role in the control of energy homeostasis and glucose metabolism in health and metabolic diseases. They act in hypothalamic nuclei to differentially control food intake, energy expenditure, and white adipose tissue distribution. Estrogen actions in skeletal muscle, liver, adipose tissue, and immune cells are involved in insulin sensitivity as well as prevention of lipid accumulation and inflammation. Estrogen deficiency promotes metabolic dysfunction, predisposing one to obesity, metabolic syndrome, and type 2 diabetes (Mauvais-Jarvis et al., 2013). The role of estrogens in male reproduction and other organs remains unclear. Although estrogen receptors (ER) are widely distributed in males, estrogen levels are much lower than in females. However, it was stated that estrogen regulates efferent ductile function and germ cell development in male mice, protects against cardiovascular disease and affects lipid profiles and insulin resistance in men (Heine et al., 2000).

Phytoestrogens are nonsteroidal compounds found in many legumes and are particularly abundant in soy products. The two main soy isoflavone conjugates, genistin and daidzein, are not estrogenic, but they are hydrolyzed in the intestinal tract to form the aglycones, genistein and daidzein, which have estrogenic activity (Setchell et al., 2002). Phytoestrogens have the capacity to bind both ER $\alpha$ and $\beta$ and to mimic estrogenic actions (Kuiper et al., 1998). Because both ERs are present in tissues responsible for the regulation of metabolism (hypothalamus, adipose tissue, skeletal muscle, pancreatic $\beta$-cells), the implication that phytoestrogens regulate metabolism appears plausible.

There is also increasing evidence that phytoestrogens counteract the cellular derangements that are responsible for the development of obesity and metabolic syndrome (Jungbauer and Medjakovic, 2014). One of the mechanisms that could be involved is an alteration in food intake. Daidzein has been reported to reduce food intake as well as body weight in obese rats (Crespillo et al., 2011; Rivera et al., 2013). In addition, research has shown marked differences in the metabolism of mice fed estrogen-free diets compared to those fed diets containing phytoestrogens beginning at conception, with the absence of dietary soy isoflavones resulting in increased body weight, decreased glucose tolerance and other metabolic changes associated with obesity (Cederroth et al., 2007).

Based on these observations, our hypothesis proposes that removing phytoestrogens from the diet in adult life of male rats affects food intake, resulting in obesity and diabetes. Therefore, the aim of the present study was to investigate whether phytoestrogens withdrawal in adult male rats could alter the hypothalamic signals that regulate food intake, affecting body weight and blood glucose control.

\section{Materials and methods}

\subsection{Animals, diets, and dietary treatment}

All procedures were approved by the Ethical Committee of the School of Biochemistry and Biological Sciences (University of Litoral) and were performed in accordance with the principles and procedures outlined in the Guide for the Care and Use of Laboratory Animals issued by the U.S. National Academy of Sciences (National Research Council, Institute of Laboratory Animal Resources, 1996). Eighteen adult male Wistar rats were obtained from timed-pregnant rats of an inbred Wistar-derived strain bred at the Department of Human Physiology (Santa Fe, Argentina). From conception until the beginning of the experiment, the rats were housed in individual cages, under controlled conditions $\left(23 \pm 2{ }^{\circ} \mathrm{C}\right.$ and 12 hour lightdark cycle) with free access to a high soy-containing regular animal chow diet [high phytoestrogen (HP) diet] (Cooperación, ACA Nutrición Animal, Buenos Aires, Argentina). The phytoestrogen content of the diets was analyzed by HPLC. HP diet contained $400 \mathrm{mg} / \mathrm{kg}$ of phytoestrogens ( $210 \mathrm{mg} / \mathrm{kg}$ of daidzein and $190 \mathrm{mg} / \mathrm{kg}$ of genistein). These phytoestrogens came from the soy contained in the chow and are consistent with a soy protein content of approximately $23 \%$ in the HP diet. When the animals reached 250-300 g (approximately 3 months old) they were randomly divided into three weightmatched groups and submitted to the following dietary treatment for 15 weeks. One group was used as control and had ad libitum access to the same HP diet. To evaluate the effects of withdrawing phytoestrogens from the diet, another group was fed a soy-free diet [low phytoestrogen (LP)] (Zeigler Phytoestrogen Reduced Rodent Diet I; Zeigler Brothers, Gardner, PA, USA). Phytoestrogens levels were undetectable by HPLC analysis in this diet. This LP diet was similar to HP in all other aspects besides being soy-free. LP and HP diets were equivalent in terms of carbohydrate, protein and fat content. Considering reports that the absence of dietary phytoestrogens during pregnancy resulted in obesity during later adulthood in mice (Ruhlen et al., 2008), the last group was fed the same HP diet supplemented with $25 \mathrm{~g}$ of lard per $100 \mathrm{~g}$ of food as a source of dietary fat [high phytoestrogen-high fat (HP-HF)]. This has been widely reported as a useful model to induce obesity and metabolic syndrome (Buettner et al., 2006).

Energy content was similar for HP and LP diets (3400 vs. $3600 \mathrm{kcal} / \mathrm{g}$, physiological fuel value). For the HP-HF diet, the energy content was $4717 \mathrm{kcal} / \mathrm{g}$, of which $45 \%$ consisted of saturated fat.

Body weights were recorded weekly and food intake daily during the experimental period. Food intake was determined by the weight difference between offered and remaining food, adjusted to the waste by collecting food spillage. Energy intake was calculated by multiplying these amounts of ingested food with the respective energy contents. On the 14 th week, an intraperitoneal glucose tolerance test (ipGTT) was performed as will be described later. At the end of the dietary treatments, rats were euthanized by decapitation. Trunk blood was collected, samples were centrifuged and serum was immediately used or frozen and stored at $-80{ }^{\circ} \mathrm{C}$ until analysis. Epididymal and perirenal fat pads were dissected and weighed. Immediately after euthanization, the brain was removed from the skull, and the mediobasal hypothalamus was dissected (according to Paxinos atlas coordinates -1.0 to $-4.5 \mathrm{~mm}$ from Bregma and $3 \mathrm{~mm}$ in depth) (Paxinos and Watson, 2005), snap-frozen in liquid nitrogen, and stored at $-80{ }^{\circ} \mathrm{C}$ until RNA isolation.

\subsection{RNA isolation, reverse transcription and real-time quantitative PCR}

Total RNA was isolated from the hypothalamus using TRIzol (Invitrogen, Carlsbad, CA, USA) according to the manufacturer's protocol. Two micrograms of total RNA were generated via reverse transcription using 200 pmol of random primers (Promega, Madison, WI, USA) and Moloney Murine Leukemia Virus reverse transcriptase (300 units; Promega, Madison, WI, USA). Twenty units of the ribonuclease inhibitor RNAout (Invitrogen Argentina, Buenos Aires, Argentina) and $100 \mathrm{nmol}$ of a deoxynucleotide triphosphate (dNTP) mixture were added to each reaction tube at a final volume of $30 \mu \mathrm{l}$ of $1 \times$ reverse transcriptase buffer. Reverse transcription was performed at $37{ }^{\circ} \mathrm{C}$ for $90 \mathrm{~min}$ and at $42{ }^{\circ} \mathrm{C}$ for $15 \mathrm{~min}$. Reactions were stopped by heating at $80^{\circ} \mathrm{C}$ for $5 \mathrm{~min}$ and cooling on ice. Each reverse-transcribed product was diluted with RNAse free water to a final volume of $60 \mu \mathrm{l}$ and further amplified in duplicate.

For cDNA amplification, $5 \mu \mathrm{l}$ of cDNA was combined with HOT FIREPol EvaGreen qPCR Mix Plus (Solis BioDyne; Biocientífica, Rosario, Argentina) and $10 \mathrm{pmol}$ of each primer (Invitrogen, Buenos Aires, Argentina) to a final volume of $20 \mu$ l. Primer pairs used for ribosomal protein L19 (housekeeping gene), Agrp, Pomc, Cart, Npy, the long form of the leptin receptor $(o b-R b)$, the insulin receptor (InsR), and $E R \alpha$ and $\beta$ are shown in Table 1. cDNA levels were 
Table 1

Sequences of primers used for real time quantitative PCR.

\begin{tabular}{|c|c|c|c|}
\hline $\begin{array}{l}\text { Gene } \\
\text { name }\end{array}$ & $\begin{array}{l}\text { Accession } \\
\text { number }\end{array}$ & Primer sequences & Size \\
\hline L19 & NM_031103 & $\begin{array}{l}\text { F: 5'-AGCCTGTGACTGTCCATTCC-3' } \\
\text { R: 5'-TGGCAGTACCCTTCCTCTTC-3' }\end{array}$ & $99 \mathrm{pb}$ \\
\hline Pomc & NM_139326.2 & $\begin{array}{l}\text { F: 5'-CCTCCTGCTTCAGACCTCCATA-3' } \\
\text { R: 5'-TGTTCATCTCCGTTGCCTGG-3' }\end{array}$ & $159 \mathrm{pb}$ \\
\hline Cart & NM_017110.1 & $\begin{array}{l}\text { F: 5'-GCTCAAGAGTAAACGCATTCC-3' } \\
\text { R: 5'-AAGAATTGCAAGAAGTTCCTCG-3' }\end{array}$ & $143 \mathrm{pb}$ \\
\hline Npy & NM_012614.1 & $\begin{array}{l}\text { F: 5'-CTTAATGAGAGAAAGCACAG-3' } \\
\text { R: 5'-AACTAGGAAAAGTCAGGAGA-3' }\end{array}$ & $101 \mathrm{pb}$ \\
\hline Agrp & NM_033650.1 & $\begin{array}{l}\text { F: 5'-TTGGCAGAGGTGCTAGATCCA-3' } \\
\text { R: 5'-AGGACTCGTGCAGCCTTACAC-3' }\end{array}$ & $108 \mathrm{pb}$ \\
\hline$o b-R b$ & NM_012596.1 & $\begin{array}{l}\text { F: 5'-GGATGAGTGTCAGAGTCAA-3' } \\
\text { R: 5'-CTCTTCATCAGTTTCCACTG-3' }\end{array}$ & $80 \mathrm{pb}$ \\
\hline $\operatorname{InsR}$ & NM_017071.2 & $\begin{array}{l}\text { F: 5'-TCTCTCCAGGAAACTACAGTGT-3' } \\
\text { R: 5'-AAAATAGGTGGGTTCTGTCC-3' }\end{array}$ & $80 \mathrm{pb}$ \\
\hline$E R \alpha$ & NM_012689 & $\begin{array}{l}\text { F: 5'-ACTACCTGGAGAACGAGCCC-3' } \\
\text { R: 5'-CCTTGGCAGACTCCATGATC-3' }\end{array}$ & $153 \mathrm{pb}$ \\
\hline$E R \beta$ & NM_012754 & $\begin{array}{l}\text { F: 5'-TTCTGGGCACCTGTCTCCTT-3' } \\
\text { R: 5'-TAACAGGGCTGGCACAACTG-3' }\end{array}$ & $166 \mathrm{pb}$ \\
\hline
\end{tabular}

L19: ribosomal protein (housekeeping gene); Pomc: Proopiomelanocortin; Cart: Cocaine-amphetamines related transcript; Npy: neuropeptide Y; Agrp: agouti related protein; $O b-R b$ : long form of leptin receptor, InsR: insulin receptor, $E R \alpha$ and $\beta$ : estrogen receptors alpha and beta.

determined by using a real-time PCR system StepOne Cycler (Applied Biosystems Inc., Life Technologies, Carlsbad, CA, USA). Product purity was confirmed by dissociation curves, and random samples were subjected to agarose gel electrophoresis. Negative DNA template controls were included in all of the assays, and yielded no consistent amplification. The threshold cycles (Ct) and PCR efficiency were calculated using Step One software (Applied Biosystems, Life Technologies, Carlsbad, CA). Fold change from HP values was determined using the delta-delta Ct method (Pfaffl, 2001). No significant differences in $\mathrm{Ct}$ values were observed for L19 between the different experimental groups.

\subsection{Intraperitoneal glucose tolerance test (ipGTT)}

On week 14 of the treatment, rats were fasted overnight and were then given an i.p. injection of glucose $(2 \mathrm{~g} / \mathrm{kg})$. Blood samples were taken from the tail vein, and glucose was measured using commercially available kits (Wiener Lab, Argentina) at 0 (fasting), 30, 60, 90 and 120 minutes after glucose administration (Wang et al., 2011). The total area under curve (AUC) for glucose during the ipGTT (2-h glucose area under curve) was calculated using Origin software (Origin, Origin Lab Corporation, MA USA).

\subsection{Circulating hormone measurements}

The circulating levels of leptin were determined by specific RIAs developed in our laboratories (Giovambattista et al., 2006). Serum insulin was assessed by RIA using an anti-rat insulin antibody (Sigma, St. Louis, Missouri, USA) and standard rat insulin provided by Laboratorios Beta (Buenos Aires, Argentina). TSH was determined by competitive RIA according to the procedure outlined by Catalano et al. (2005). The levels of total T4, estradiol and testosterone were measured using competitive RIA kits (Immunotech, Marseille, France). Insulin resistance was evaluated according to the homeostasis model assessment (HOMA). The HOMA index was calculated as [fasting insulin $(\mathrm{IU} / \mathrm{ml}) \times$ fasting glucose $(\mathrm{mol} / \mathrm{l})] / 22.5$ (Matthews et al., 1985).

\subsection{Statistical analysis}

Data (expressed as the means \pm SEM) were statistically analyzed by one-way ANOVA using IBM SPSS Statistics 19 software (IBM Inc., Armonk, NY, USA). Weekly body weights were compared via repeated measures ANOVA. Post-hoc multiple comparisons were made using Tukey's critical range test. Differences were considered significant at $\mathrm{p}<0.05$.

\section{Results}

3.1. Phytoestrogen withdrawal increased adipose tissue, body weight and energy intake

When the animals were fed with the phytoestrogen-free diet, their body weights significantly increased from the first week (Fig. 1). The body weight of LP rats during the 15-week observation period was similar or higher than that observed in the HP-HF group. This was also reflected in the final body weight, as seen in Table 2.

To determine whether there was a region-specific fat gain, selected fat deposits (epididymal and perirenal) were excised and weighed. Consistent with the changes in body weight, phytoestrogen withdrawal also increased body fat. Compared with the HP rats, LP animals had significantly greater amounts of epididymal and perirenal fat, expressed both in grams (absolute value) and as a percentage of body weight (Table 2). This was also noticeable with respect to the HP-HF group, as both fat pad weights were significantly higher in the LP group when expressed as a percentage of body weight (Table 2 ).

In close relation to this, food intake was strikingly increased in LP, but not in HP-HF rats, demonstrating that phytoestrogen withdrawal induces hyperphagia. Given that the HP-HF diet was hyperenergetic, energy intake was 50\% greater in the HP-HF rats compared to HP. However, the hyperphagia observed in LP rats led to a $75 \%$ increase in energy intake compared to the HP group and a $17 \%$ increase compared to the HP-HF group (Table 2).

Table 2

Final body and adipose tissue weights, food and energy intake.

\begin{tabular}{|c|c|c|c|c|}
\hline & HP & LP & $\mathrm{HP}-\mathrm{HF}$ & $p$ value \\
\hline Final body weight & $455 \pm 7^{a}$ & $483 \pm 6^{b}$ & $478 \pm 6^{b}$ & 0.014 \\
\hline \multicolumn{5}{|l|}{ Epididymal fat pads weight } \\
\hline g & $13.88 \pm 0.78^{a}$ & $22.28 \pm 0.68^{\mathrm{b}}$ & $20.05 \pm 0.93^{b}$ & $<0.001$ \\
\hline g/100 g of body weight & $3.05 \pm 0.13^{a}$ & $4.61 \pm 0.12^{\mathrm{b}}$ & $4.19 \pm 0.16^{c}$ & $<0.001$ \\
\hline \multicolumn{5}{|l|}{ Perirenal fat pads weight } \\
\hline g & $15.33 \pm 1.15^{\mathrm{a}}$ & $26.72 \pm 0.57^{\mathrm{b}}$ & $23.45 \pm 0.91^{\mathrm{b}}$ & $<0.001$ \\
\hline $\mathrm{g} / 100 \mathrm{~g}$ of body weight & $3.36 \pm 0.20^{\mathrm{a}}$ & $5.53 \pm 0.08^{\mathrm{b}}$ & $4.90 \pm 0.14^{\mathrm{c}}$ & $<0.001$ \\
\hline Food intake $(\mathrm{g} / \mathrm{d})$ & $15.47 \pm 0.22^{\mathrm{a}}$ & $22.23 \pm 0.25^{b}$ & $16.87 \pm 0.15^{\mathrm{a}}$ & $<0.001$ \\
\hline Energy intake (kJ/d) & $194.1 \pm 2.8^{\mathrm{a}}$ & $354.1 \pm 4.0^{\mathrm{b}}$ & $302.4 \pm 0.9^{c}$ & $<0.001$ \\
\hline
\end{tabular}

HP, high phytoestrogen; LP, low phytoestrogen; HP-HF, high phytoestrogen-high fat.

Data shown are presented as the mean \pm SEM $(n=6)$. Different superscript letters indicate significant differences at $p<0.05$ by Tukey's test after one-way ANOVA. 


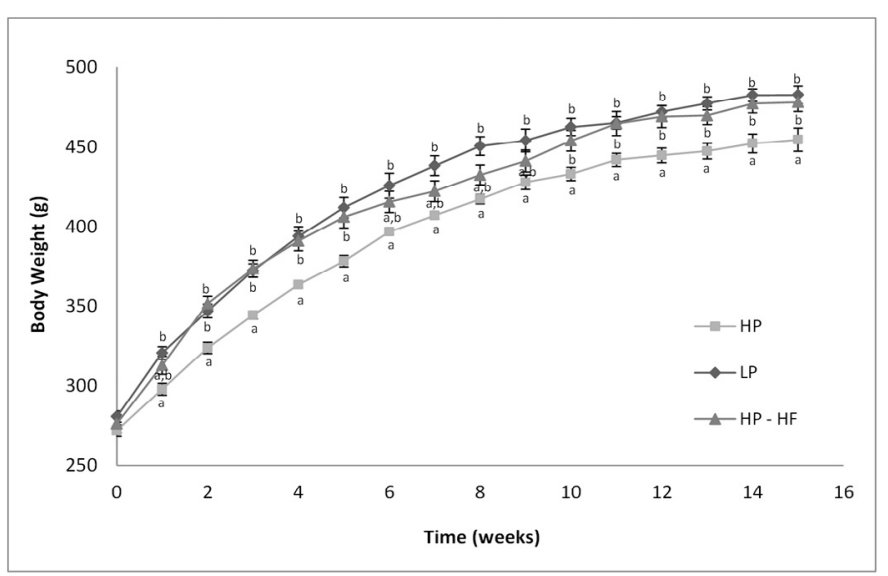

Fig. 1. Body weight of rats fed with high phytoestrogen (HP), low phytoestrogen (LP) or high phytoestrogen-high fat (HP-HF) diets for 15 weeks. Different letters indicate significant differences at $\mathrm{p}<0.05$ by Tukey's test after repeated measures ANOVA.
3.2. Increased energy intake was associated with changes in the hypothalamic expression of neuropeptides

The effect of phytoestrogen withdrawal on the expression of neuropeptides in the hypothalamus was assessed to investigate the mechanisms involved in increased food intake. As seen in Fig. 2, phytoestrogen withdrawal induced an orexigenic response by significantly reducing anorexigenic POMC and increasing orexigenic AgRP mRNA expression compared to the HP rats $(p<0.001)$. Nevertheless, NPY and CART mRNA levels were unchanged. The greater energy intake observed in HP-HF with respect to HP fed rats was linked to reduced POMC mRNA levels ( $<<0.001$ ), which was concomitant with a paradoxical decrease in NPY $(\mathrm{p}<0.001)$ (Fig. 2).

\subsection{Phytoestrogen withdrawal affected blood hormones}

The blood hormone profile of the animals is shown in Table 3. The obese phenotype induced by LP and HP-HF diets was concomitant with greater leptin levels and a reduction in serum testosterone

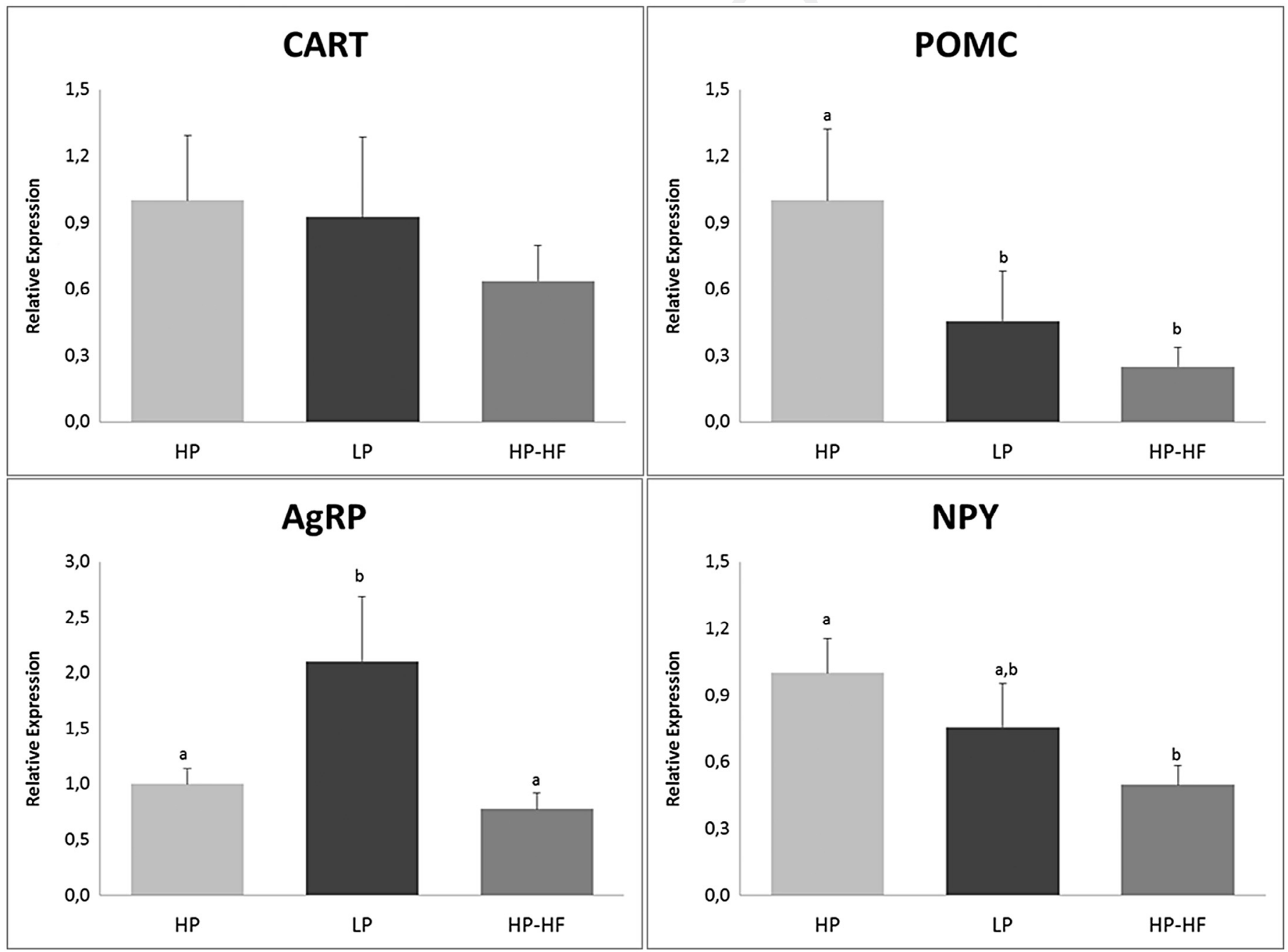

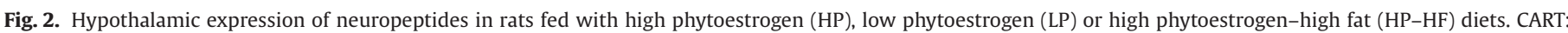

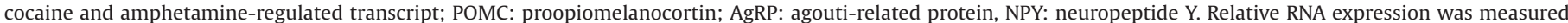

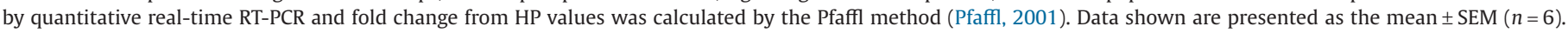
Different letters indicate significant differences at $p<0.05$ by Tukey's test after one way ANOVA. 
Table 3

Blood hormone profile.

\begin{tabular}{|c|c|c|c|c|}
\hline & $\mathrm{HP}$ & LP & HP-HF & $\mathrm{p}$ value \\
\hline Leptin (ng/mL) & $2.12 \pm 0.30^{\mathrm{a}}$ & $4.48 \pm 0.97^{b}$ & $4.48 \pm 0.09^{b}$ & 0.013 \\
\hline \multicolumn{5}{|l|}{$\begin{array}{l}\text { Thyroid system } \\
\text { hormones }\end{array}$} \\
\hline Total T4 (nmol/L) & $22.27 \pm 1.11^{\mathrm{a}}$ & $39.91 \pm 1.54^{\mathrm{b}}$ & $27.93 \pm 4.38^{\mathrm{a}}$ & 0.001 \\
\hline $\mathrm{TSH}(\mathrm{ng} / \mathrm{mL})$ & $3.52 \pm 0.48$ & $2.43 \pm 0.24$ & $3.61 \pm 0.26$ & 0.036 \\
\hline \multicolumn{5}{|l|}{ Sex hormones } \\
\hline $\begin{array}{l}\text { Testosterone } \\
\text { (ng/mL) }\end{array}$ & $1.03 \pm 0.26^{a}$ & $0.46 \pm 0.10^{\mathrm{b}}$ & $0.42 \pm 0.10^{\mathrm{b}}$ & 0.030 \\
\hline Estradiol (pg/mL) & $5.60 \pm 0.51^{\mathrm{a}}$ & $2.20 \pm 0.70^{\mathrm{b}}$ & $5.12 \pm 0.41^{\mathrm{a}}$ & 0.030 \\
\hline
\end{tabular}

HP, high phytoestrogen; LP, low phytoestrogen; HP-HF, high phytoestrogen-high fat. Data shown are presented as the mean \pm SEM $(n=6)$. Different superscript letters indicate significant differences at $\mathrm{p}<0.05$ by Tukey's test after one-way ANOVA.

with respect to HP group. Phytoestrogen withdrawal raised total T4 and reduced estradiol vs. HP diet. TSH showed lower values only in LP group ( $\mathrm{p}=0.036)$, not reaching statistical significance using Tukey's critical range test.
3.4. Obese rats showed reduced hypothalamic expression of estrogen receptor alpha

The obese phenotype induced by LP and HP-HF diets was concomitant with a reduction in ER $\alpha$ mRNA levels in the hypothalamus (Fig. 3). On the other hand, ER $\beta$ expression remained unchanged by the treatment. Phytoestrogen withdrawal did not alter ob-Rb or InsR mRNA expression; however, InsR expression was reduced in animals fed the HP-HF diet, as seen in Fig. 3.

\subsection{Phytoestrogen withdrawal impaired glucose metabolism}

Glucose tolerance tests were performed to assess glucose homeostasis. Fasting blood glucose levels and the 30- and 120minute time points of the glucose tolerance test were higher in the LP group compared to the HP animals (Fig. 4), which significantly increased the AUC of the test (Table 4). Phytoestrogen withdrawal also increased insulin and the HOMA index (Table 4), indicating insulin resistance. Although the HP-HF diet did not affect basal glucose or insulin concentrations, the AUC of the ipGTT was also

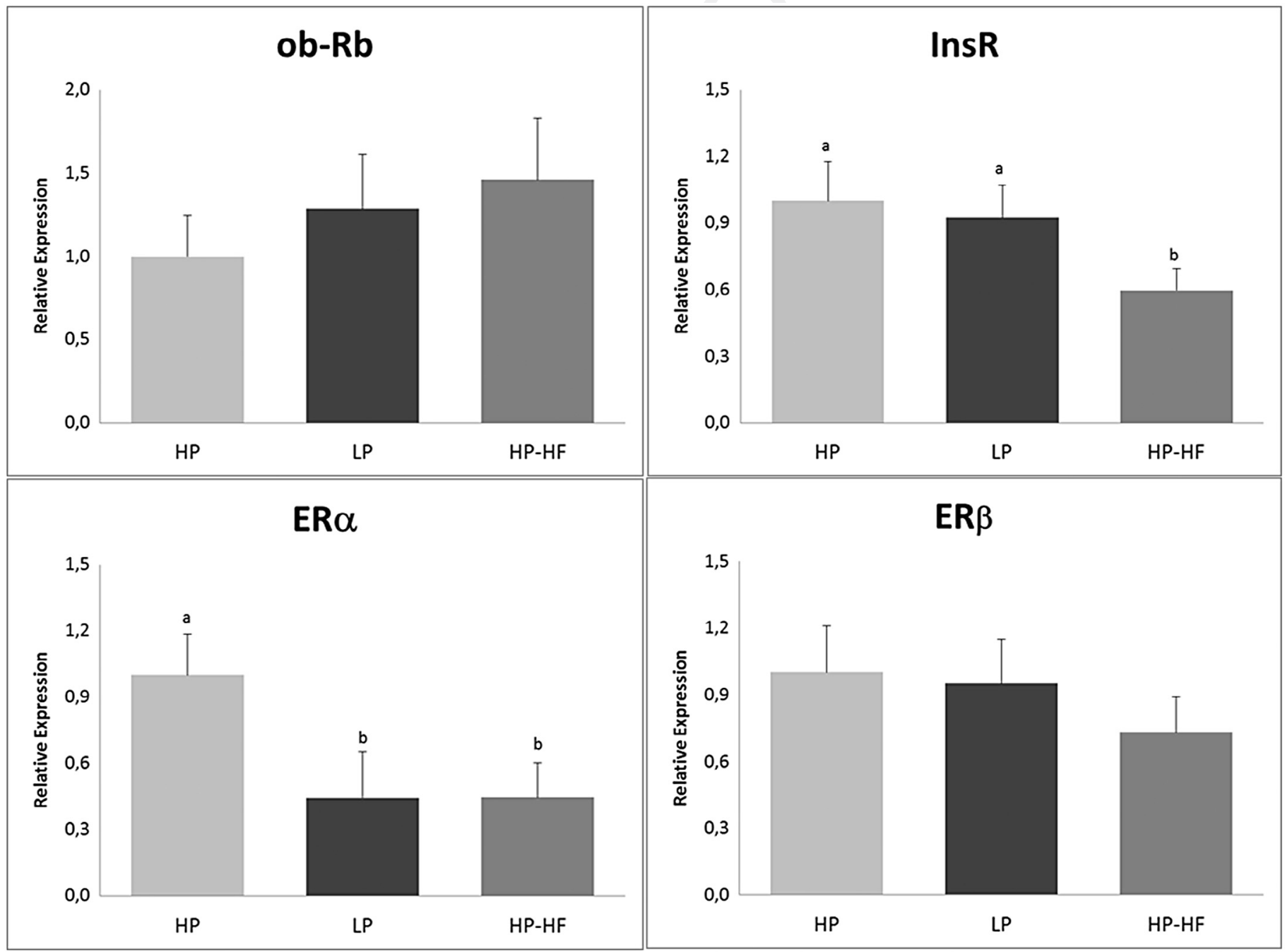

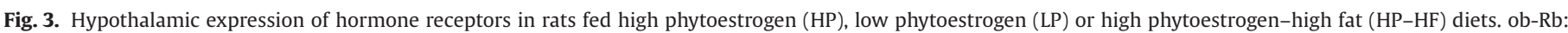

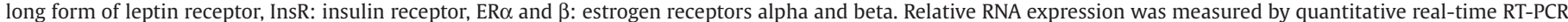

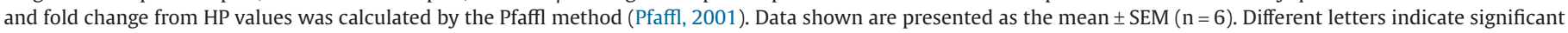
differences at $\mathrm{p}<0.05$ by Tukey's test after one-way ANOVA. 


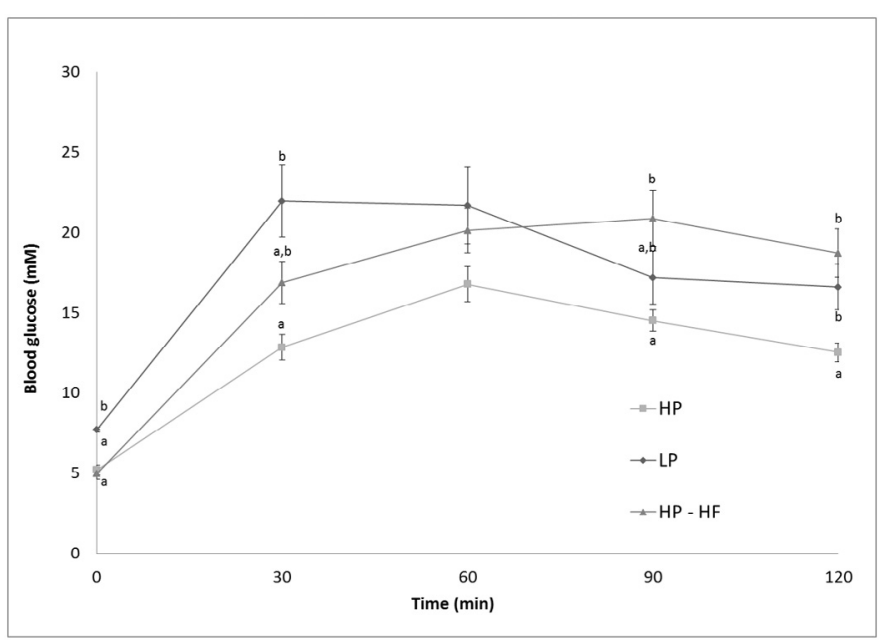

Fig. 4. Intraperitoneal glucose tolerance test (ipGTT) of rats fed with high phytoestrogen (HP), low phytoestrogen (LP) or high phytoestrogen-high fat (HP$\mathrm{HF}$ ) diets for 14 weeks. Data shown are presented as the mean $\pm \operatorname{SEM}(n=6)$. Different letters indicate significant differences at $p<0.05$ by Tukey's test after one-way ANOVA.

elevated compared to the HP group, reflecting an emerging impairment in glucose tolerance.

\section{Discussion}

This study demonstrates for the first time that phytoestrogen withdrawal in the adult stage of life induces obesity in male rats. This was associated with hyperphagia and altered hypothalamic regulation of food intake, changes in circulating hormones and impaired glucose metabolism.

Estrogens have been shown to influence body weight, food intake and adipose tissue deposition (Brown and Clegg, 2010). Multiple studies have suggested that, similar to estrogens, dietary phytoestrogens play a beneficial role in reducing obesity and diabetes (Cederroth and Nef, 2009b). In the present study, male rats that stopped receiving dietary phytoestrogens in adult life displayed significantly increased adipose tissue and body weights compared to HP fed animals. These results are consistent with Ruhlen et al. (2008) and Cederroth and Nef (2009a), who reported that removing phytoestrogens from rodent feed during pregnancy and lactation in CD-1 mice produces an obese phenotype in the litter and impairs glucose tolerance. Our work demonstrates for the first time that if male rats consume phytoestrogens until they reach adult life, when the feed is replaced by a low phytoestrogen diet, an obese phenotype with alterations in glucose metabolism emerges. In fact, epididymal and perirenal fat pads were heavier and body weight was similar to rats fed a high saturated fat diet, which is widely known to induce marked weight gain (Buettner et al., 2006).

In almost all commercially available rodent diets, soy is used as a main source of protein. As a consequence, experimental animals have been bred and maintained for many generations on

Table 4

Glucose metabolism parameters.

\begin{tabular}{lcrrr}
\hline & HP & LP & HP-HF & p value \\
\hline Insulin (mU/L) & $28.60 \pm 0.86^{\mathrm{a}}$ & $42.01 \pm 0.79^{\mathrm{b}}$ & $30.64 \pm 1.84^{\mathrm{a}}$ & $<0.001$ \\
Fasting glucose $(\mathrm{mM})$ & $5.19 \pm 0.31^{\mathrm{a}}$ & $7.70 \pm 0.14^{\mathrm{b}}$ & $4.96 \pm 0.37^{\mathrm{a}}$ & $<0.001$ \\
HOMA & $6.59 \pm 0.46^{\mathrm{a}}$ & $14.40 \pm 0.49^{\mathrm{b}}$ & $6.86 \pm 0.86^{\mathrm{a}}$ & $<0.001$ \\
AUC ipGTT & $1589 \pm 68^{\mathrm{a}}$ & $2174 \pm 171^{\mathrm{b}}$ & $2090 \pm 141^{\mathrm{b}}$ & 0.015 \\
\hline
\end{tabular}

HP, high phytoestrogen; LP, low phytoestrogen; HP-HF, high phytoestrogen-high fat. Data shown are presented as the mean \pm SEM $(n=6)$. Different superscript letters indicate significant differences at $\mathrm{p}<0.05$ by Tukey's test after one-way ANOVA. soy-containing feed, thus driving selection for traits that allow them to tolerate the relatively high levels of phytoestrogens present in commonly used commercial feeds (Ruhlen et al., 2008). This fact focused our interest on the effects of a commercial diet as a relevant model of phytoestrogen intake, rather than exposing animals to pure phytoestrogens, which would represent a more controlled but less pertinent experimental design.

Replacing regular lab chow by low phytoestrogen diet results in obesity due to an anabolic process, with changes in food and energy intake primarily mediating weight gain. However, this was not observed in high fat fed rats; hyperphagia was not present, and the greater energy intake was a result of the greater energy content of the diet. Other authors (Cederroth et al., 2007) reported that the absence of dietary soy isoflavones from conception results in increased body weight not related to a greater food intake but to decreased energy expenditure and locomotor activity in CD-1 mice. The different animal models and periods of exposure used may be involved in the contrasting results observed. Exposure to estrogenic substances during early life produces organizational effects that may have consequences in the adult life, for instance, in the physiological systems regulating feeding and energy balance (Nohara et al., 2011). Our work implies a switch to a low phytoestrogen diet in the adulthood that generates obesity and glucose homeostasis impairment. Future research could be focused to investigate if these effects are reversible.

Anorexigenic (POMC/CART) and orexigenic (NPY/AgRP) neurons regulate energy balance in the arcuate nucleus of the mediobasal hypothalamus. Changing the HP by the LP diet significantly decreased POMC and increased AgRP mRNA in the hypothalamus, implying that energy intake is increased at least partially through these systems. Again, the mechanisms activated by the high fat diet are different, involving only decreased POMC expression. Our results are in agreement with Cederroth et al. (2007), who reported that the mRNA levels of AgRP in the hypothalamus were also regulated by dietary phytoestrogens. Also consistent with our data, AgRP gene expression was repressed in clonal NPY/AgRP hypothalamic neurons exposed to $17 \beta$-estradiol (Titolo et al., 2006). There is also evidence that estrogens act directly on POMC neurons and regulate their cellular activity (Mauvais-Jarvis et al., 2013). It has been reported that estradiol treatment may elevate POMC tone in wildtype animals, in part by increasing the number of excitatory synapses, an effect similar to that induced by leptin (Gao et al., 2007). Therefore, this could be a plausible mechanism by which LP diet could decrease the activation of this group of neurons. In this sense, the present data allow us to hypothesize that the increased AgRP as well as the reduced POMC expression mediate an initial hyperphagic response that onsets obesity, hyperleptinemia and diabetes. With respect to the effect of high fat diet on POMC expression, our results are consistent with Marco et al., who reported that a high fat diet induces hypermethylation of the hypothalamic POMC promoter, affecting transcription factor binding and disrupting its activity (Marco et al., 2013).

Leptin promotes negative energy balance by signaling in the brain, and the hypothalamus is a key region for the control of food intake by this hormone. In the arcuate nucleus, leptin suppresses the activity of neurons that contain the orexigenic peptides NPY and AgRP, and stimulates the activity of neurons that release anorexigenic peptides, POMC and CART. This mechanism becomes disrupted in most obese individuals, resulting in a state known as central leptin resistance. Therefore, increased leptin levels may fail to activate POMC neurons, as is shown by our results. However, high fat fed rats showed hyperleptinemia with decreased POMC and NPY expression. Younes-Rapozo et al. (2013) reported that NPY does not always maintain a direct relation with leptin action. In several programmed models in which the adult animal develops central leptin resistance, lower hypothalamic NPY was observed. Although the 
expression of the hypothalamic leptin receptor $(\mathrm{Ob}-\mathrm{Rb})$ remained unchanged, other mechanisms, such as a reduced leptin signaling, an alteration in the downstream pathway or a low penetration of the blood brain barrier, may be responsible for a central leptin resistant status (McNay et al., 2012).

Leptin may also alter thyroid function not only by affecting the thyroid axis but also by raising thyroid gland weight and the secretion of T3 and T4 through a direct mechanism involving the thyroid gland Ob-Rb (Nowak et al., 2002). In agreement with this, our obese hyperleptinemic phytoestrogen deprived rats showed higher circulating total T4 and slightly (but not significant) decreased TSH that may be a consequence of negative feedback from T4. However, this effect is not observed in high fat fed rats, demonstrating that a rise in circulating leptin alone may not be sufficient to affect thyroid function. In this regard, phytoestrogens, particularly genistein, was reported to reduce thyroid hormone levels, as it interacts with key pathways involved in thyroid hormones synthesis, metabolism and thyroid hormone transport proteins (Marini et al., 2012). Therefore, and according to our results, we can hypothesize that phytoestrogen withdrawal may produce an increase in total T4 and a consequent reduction in TSH. This mechanism might be potentiated by elevated circulating leptin levels.

The fact that dietary phytoestrogens have effects on energy homeostasis through estrogen-mimetics is a clearly plausible hypothesis. Our results show decreased serum testosterone and estradiol concentrations in LP fed rats. Although in healthy adult women high dietary intake of soy products has been reported to decrease circulating $E_{2}$ (Lu et al., 2000; Nagata et al., 1997), the reduction observed in our animal model is in line with the obese phenotype observed which resembles menopause. A similar obese phenotype is also observed in estrogen-deficient ovariectomized rats (Clegg et al., 2006; Wade, 1972). Therefore, a plausible mechanism by which the replacement of HP by LP diet may exert some of the observed effects could be through a reduction in circulating $\mathrm{E}_{2}$ levels. In males, $\mathrm{E}_{2}$ is produced in extragonadal sites, mainly adipose tissue, bone and brain by local tissue aromatization from circulating testosterone (Simpson, 2003). It has been widely reported that excess adipose tissue, as observed in LP and HP-HF rats, may result in elevated aromatization, (Michalakis et al., 2013), but quantitatively the main estrogen produced is estrone, which has a weak estrogenic activity (Nelson and Bulun, 2001). On the other hand, the specific effects of phytoestrogens on aromatase activity are controversial. Some authors have reported that phytoestrogens can competitively inhibit the aromatase enzyme in peripheral tissues (Ibrahim and Abul-Hajj, 1990), but other in vitro studies show that genistein increases aromatase activity in rat ovarian follicles (Myllymaki et al., 2005). Therefore, the lack of dietary phytoestrogens may decrease aromatase activity and consequently reduce circulating estradiol levels, as is observed in this work. In agreement with this, and in line with our results, Jones et al. (2000) showed that mice of both sexes lacking the aromatase enzyme, which cannot synthesize $E_{2}$, develop obesity associated with hyperleptinemia and hyperinsulinemia.

It has been reported that obesity affects fertility, inducing hypogonadism in male animals (Angel Sanchez-Garrido et al., 2014) and affecting prostate structure and function (Ribeiro et al., 2012). Nutritional stress, especially the consumption of high fat diets, has a profound deleterious impact on gonadotropic function and precipitates neuroendocrine reproductive senescence in the male. One of the parameters affected is testosterone levels, which is decreased in obese male rats (Ribeiro et al., 2012), in agreement with our results in both phytoestrogen deprived and high fat fed animals.

The affinity of phytoestrogens for estrogen receptors produces effects on a large number of estrogen-regulated systems, including the metabolic, reproductive, and central nervous systems. A significant characteristic of phytoestrogens is their capacity to bind to both ER $\alpha$ and $\beta$ (Kuiper et al., 1997). However, only ER $\alpha$ has been reported to have a major influence on energy homeostasis (Heine et al., 2000). Heine et al. (2000) reported that male and female mice with total body deletion of ER $\alpha$ (ER-knock-out mice) have increased adiposity regardless of gender, suggesting an important role for this estrogen receptor in the regulation of body weight and adiposity. Other authors reported that specific silencing of ER $\alpha$ in the hypothalamus leads to metabolic syndrome (Musatov et al., 2007), demonstrating the importance of estrogens and ER $\alpha$ in the central regulation of energy balance. $\mathrm{ER} \alpha$ is more abundant in the arcuate nucleus compared to other relevant nuclei and is predominantly expressed in POMC neurons (de Souza et al., 2011). In agreement with this, we observed a reduced expression of ER $\alpha$ and POMC not only in phytoestrogens-deprived animals but also in high fat fed rats. Although ob-Rb also colocalizes with ER $\alpha$ in the arcuate nucleus (Fuente-Martin et al., 2013), no changes were observed in this receptor. Why hypothalamic ER $\alpha$ is reduced in both LP and high fat fed animals remains unknown. Several studies suggested that the estrogen and leptin systems are related via functional cross talk. For example, estrogens have been shown to regulate the expression of leptin (Casabiell et al., 1998; Tsuruta et al., 2004) and its receptor (Bennett et al., 1998) in adipose tissue and brain, respectively. Reciprocally, leptin stimulates ovarian cancer cell growth involving ER $\alpha$ transcriptional activation via the STAT-3 signaling pathways (Choi et al., 2011). Therefore, the high circulating leptin level characteristic of obese animals may be involved in the low expression of ER $\alpha$ observed, although further studies are needed to substantiate this hypothesis.

The decreased hypothalamic ER $\alpha$ signaling via a reduction of circulating $E_{2}$ in LP fed rats may be an alternative mechanism by which phytoestrogen withdrawal exerts some of the observed effects. Adipose tissue hypertrophy and hyperplasia, insulin resistance and glucose intolerance (see discussion later) seem to be mediated by this pathway, unlike energy intake or testosterone levels (Heine et al., 2000).

Regarding glucose metabolism, replacing commercial animal feed by a low phytoestrogen diet induced remarkable alterations resulting in impaired glucose tolerance. The high levels of fasting glucose combined with elevated circulating insulin, the consequent high HOMA index and the altered ipGTT reflect that removing phytoestrogens from the diet may induce insulin resistance and diabetes. These results are in agreement with other authors (Ruhlen et al., 2008), who reported that 3 months old male rats exposed to a low phytoestrogen diet from gestation presented impaired glucose clearance compared with males fed a phytoestrogen rich diet. Cederroth et al. (2008) reported that dietary phytoestrogens improve glucose metabolism via activation of AMPK, a major sensor of energy status. The authors propose a direct effect of phytoestrogens on adipose tissue through ER $\alpha$ (Hwang et al., 2005), as in vitro exposure of 3T3-L1 adipocytes to genistein has been reported to significantly activate AMPK. Other studies propose a similar effect of phytoestrogens in muscle cells, with increased insulin-stimulated IRS-1/PI3K/Akt pathway mediated by reduced phosphorylation of IRS-1 through AMPK activation and S6K1 inhibition (Arunkumar and Anuradha, 2012; Cheong et al., 2014).

Glucose metabolism impaired by phytoestrogen withdrawal was even more significant than the impairment induced by high fat intake. High fat diets are generally related to obesity and insulin resistance (Buettner et al., 2006). In agreement with this, the present results show impaired glucose tolerance as evidenced by the higher AUC of the ipGTT and decreased hypothalamic InsR expression. This reflects an incipient central effect that may result in insulin resistance with elevated circulating insulin and glucose levels upon a longer dietary treatment. This provides evidence that the mechanisms by which the lack of phytoestrogens and high fat consumption affect carbohydrate metabolism may involve different pathways. 


\section{Conclusion}

The present study demonstrated that if male rats consume phytoestrogens until they reach adult life, feed replacement by a low phytoestrogen diet induces hyperphagia and increases body weight and adiposity. Energy intake is elevated and involves an orexigenic hypothalamic response with reduced POMC and increased AgRP expression. The disruption in the hypothalamic mechanisms that regulate energy intake is related to elevated leptin levels and likely leptin resistance. Some of these effects may be exerted through the capacity of phytoestrogens to bind ER $\alpha$. Changing commercial animal chow by a low phytoestrogens diet modifies endocrine homeostasis, affecting insulin, total T4, TSH and estradiol, and reflects a variety of physiological changes closely associated to obesity. One of the most remarkable alterations is the impairment of glucose homeostasis - a hallmark of insulin resistance and diabetes. Considering the observed phenotype, the hypothalamic response and the parameters of glucose metabolism, it appears that phytoestrogen withdrawal led to more pronounced manifestations of obesity and diabetes than a high fat diet. Whether the observed effects are due exclusively to phytoestrogens or also associated with soy proteins or other micronutrients remain unclear. The ubiquity of phytoestrogens in the diet of humans and laboratory animals emphasizes the necessity of further research in this field.

\section{Acknowledgements}

We thank Juan Grant and Juan C. Villarreal for technical assistance and animal care.

\section{References}

Angel Sanchez-Garrido, M., Ruiz-Pino, F., Manfredi-Lozano, M., Leon, S., Garcia-Galiano, D., Castano, J.P., et al., 2014. Obesity-induced hypogonadism in the male: premature reproductive neuroendocrine senescence and contribution of Kiss1mediated mechanisms. Endocrinology en20131584.

Arunkumar, E., Anuradha, C.V., 2012. Genistein promotes insulin action through adenosine monophosphate-activated protein kinase activation and p70 ribosomal protein S6 kinase 1 inhibition in the skeletal muscle of mice fed a high energy diet. Nutr. Res. 32, 617-625.

Bennett, P.A. Lindell, K, Karlsson, C. Robinson, I.C., Carlsson, L.M., Carlsson, B, 1998. Differential expression and regulation of leptin receptor isoforms in the rat brain: effects of fasting and oestrogen. Neuroendocrinology 67, 29-36.

Brown, L.M., Clegg, D.J., 2010. Central effects of estradiol in the regulation of food intake, body weight, and adiposity. J. Steroid Biochem. Mol. Biol. 122, 65-73.

Buettner, R., Parhofer, K.G., Woenckhaus, M., Wrede, C.E., Kunz-Schughart, L.A., Scholmerich, J., et al., 2006. Defining high-fat-diet rat models: metabolic and molecular effects of different fat types. J. Mol. Endocrinol. 36, 485-501.

Casabiell, X., Pineiro, V., Peino, R., Lage, M., Camina, J., Gallego, R., et al., 1998. Gender differences in both spontaneous and stimulated leptin secretion by human omental adipose tissue in vitro: dexamethasone and estradiol stimulate leptin release in women, but not in men. J. Clin. Endocrinol. Metab. 83, 2149-2155.

Catalano, P.N., Bonaventura, M.M., Silveyra, P., Bettler, B., Libertun, C., Lux-Lantos, V.A., 2005. GABA(B1) knockout mice reveal alterations in prolactin levels, gonadotropic axis, and reproductive function. Neuroendocrinology 82, 294-305.

Cederroth, C.R., Nef, S., 2009a. Fetal programming of adult glucose homeostasis in mice. PLoS ONE 4, e7281.

Cederroth, C.R., Nef, S., 2009b. Soy, phytoestrogens and metabolism: a review. Mol. Cell. Endocrinol. 304, 30-42.

Cederroth, C.R., Vinciguerra, M., Kuhne, F., Madani, R., Doerge, D.R., Visser, T.J., et al., 2007. A phytoestrogen-rich diet increases energy expenditure and decreases adiposity in mice. Environ. Health Perspect. 115, 1467-1473.

Cederroth, C.R., Vinciguerra, M., Gjinovci, A., Kuhne, F., Klein, M., Cederroth, M., et al., 2008. Dietary phytoestrogens activate AMP-activated protein kinase with improvement in lipid and glucose metabolism. Diabetes 57, 1176-1185.

Cheong, S.H., Furuhashi, K., Ito, K., Nagaoka, M., Yonezawa, T., Miura, Y., et al., 2014. Daidzein promotes glucose uptake through glucose transporter 4 translocation to plasma membrane in L6 myocytes and improves glucose homeostasis in type 2 diabetic model mice. J. Nutr. Biochem. 25, 136-143.

Choi, J.H., Lee, K.T., Leung, P.C., 2011. Estrogen receptor alpha pathway is involved in leptin-induced ovarian cancer cell growth. Carcinogenesis 32, 589-596.

Clegg, D.J., Brown, L.M., Woods, S.C., Benoit, S.C., 2006. Gonadal hormones determine sensitivity to central leptin and insulin. Diabetes 55, 978-987.
Crespillo, A., Alonso, M., Vida, M., Pavon, F.J., Serrano, A., Rivera, P., et al., 2011. Reduction of body weight, liver steatosis and expression of stearoyl-CoA desaturase 1 by the isoflavone daidzein in diet-induced obesity. Br. J. Pharmacol. $164,1899-1915$.

de Souza, F.S., Nasif, S., Lopez-Leal, R., Levi, D.H., Low, M.J., Rubinsten, M., 2011. The estrogen receptor alpha colocalizes with proopiomelanocortin in hypothalamic neurons and binds to a conserved motif present in the neuron-specific enhancer nPE2. Eur. J. Pharmacol. 660, 181-187.

Fuente-Martin, E., Garcia-Caceres, C., Morselli, E., Clegg, D.J., Chowen, J.A., Finan, B. et al., 2013. Estrogen, astrocytes and the neuroendocrine control of metabolism. Rev. Endocr. Metab. Disord. 14, 331-338.

Gao, Q., Mezei, G., Nie, Y., Rao, Y., Choi, C.S., Bechmann, I., et al., 2007. Anorectic estrogen mimics leptin's effect on the rewiring of melanocortin cells and Stat3 signaling in obese animals. Nat. Med. 13, 89-94.

Giovambattista, A., Piermaria, J., Suescun, M.O., Calandra, R.S., Gaillard, R.C., Spinedi, E., 2006. Direct effect of ghrelin on leptin production by cultured rat white adipocytes. Obesity (Silver Spring) 14, 19-27.

Heine, P.A., Taylor, J.A., Iwamoto, G.A., Lubahn, D.B., Cooke, P.S., 2000. Increased adipose tissue in male and female estrogen receptor-alpha knockout mice. Proc. Natl. Acad. Sci. U.S.A. 97, 12729-12734.

Hwang, J.T., Park, I.J., Shin, J.I., Lee, Y.K., Lee, S.K., Baik, H.W., et al., 2005. Genistein, EGCG, and capsaicin inhibit adipocyte differentiation process via activating AMP-activated protein kinase. Biochem. Biophys. Res. Commun. 338, 694-699.

Ibrahim, A.R., Abul-Hajj, Y.J., 1990. Aromatase inhibition by flavonoids. J. Steroid Biochem. Mol. Biol. 37, 257-260.

Jones, M.E., Thorburn, A.W., Britt, K.L., Hewitt, K.N., Wreford, N.G., Proietto, J., et al. 2000. Aromatase-deficient (ArKO) mice have a phenotype of increased adiposity. Proc. Natl. Acad. Sci. U.S.A. 97, 12735-12740.

Jungbauer, A., Medjakovic, S., 2014. Phytoestrogens and the metabolic syndrome. J. Steroid Biochem. Mol. Biol. 139, 277-289.

Kopelman, P.G., Grace, C., 2004. New thoughts on managing obesity. Gut 53 1044-1053.

Kuiper, G.G., Carlsson, B., Grandien, K., Enmark, E., Haggblad, J., Nilsson, S., et al., 1997. Comparison of the ligand binding specificity and transcript tissue distribution of estrogen receptors alpha and beta. Endocrinology 138, 863-870.

Kuiper, G.G., Lemmen, J.G., Carlsson, B., Corton, J.C., Safe, S.H., van der Saag, P.T., et al., 1998. Interaction of estrogenic chemicals and phytoestrogens with estrogen receptor beta. Endocrinology 139, 4252-4263.

Lu, L.J., Anderson, K.E., Grady, J.J., Kohen, F., Nagamani, M., 2000. Decreased ovarian hormones during a soya diet: implications for breast cancer prevention. Cancer Res. 60, 4112-4121.

Marco, A., Kisliouk, T., Weller, A., Meiri, N., 2013. High fat diet induces hypermethylation of the hypothalamic Pomc promoter and obesity in postweaning rats. Psychoneuroendocrinology 38, 2844-2853.

Marini, H., Polito, F., Adamo, E.B., Bitto, A., Squadrito, F., Benvenga, S., 2012. Update on genistein and thyroid: an overall message of safety. Front Endocrinol (Lausanne) 3, 94.

Matthews, D.R., Hosker, J.P., Rudenski, A.S., Naylor, B.A., Treacher, D.F., Turner, R.C. 1985. Homeostasis model assessment: insulin resistance and beta-cell function from fasting plasma glucose and insulin concentrations in man. Diabetologia 28, $412-419$.

Mauvais-Jarvis, F., Clegg, D.J., Hevener, A.L., 2013. The role of estrogens in contro of energy balance and glucose homeostasis. Endocr. Rev. 34, 309-338.

McNay, D.E., Briancon, N., Kokoeva, M.V., Maratos-Flier, E., Flier, J.S., 2012. Remodeling of the arcuate nucleus energy-balance circuit is inhibited in obese mice. J. Clin. Invest. 122, 142-152.

Michalakis, K., Mintziori, G., Kaprara, A., Tarlatzis, B.C., Goulis, D.G., 2013. The complex interaction between obesity, metabolic syndrome and reproductive axis: a narrative review. Metabolism 62, 457-478.

Musatov, S., Chen, W., Pfaff, D.W., Mobbs, C.V., Yang, X.J., Clegg, D.J., et al., 2007. Silencing of estrogen receptor alpha in the ventromedial nucleus of hypothalamus leads to metabolic syndrome. Proc. Natl. Acad. Sci. U.S.A. 104, 2501-2506.

Myllymaki, S., Haavisto, T., Vainio, M., Toppari, J., Paranko, J., 2005. In vitro effects of diethylstilbestrol, genistein, 4-tert-butylphenol, and 4-tert-octylphenol on steroidogenic activity of isolated immature rat ovarian follicles. Toxicol. Appl. Pharmacol. 204, 69-80.

Nagata, C., Kabuto, M., Kurisu, Y., Shimizu, H., 1997. Decreased serum estradiol concentration associated with high dietary intake of soy products in premenopausal Japanese women. Nutr. Cancer 29, 228-233.

National Research Council, Institute of Laboratory Animal Resources, 1996. Guide for the Care and Use of Laboratory Animals. National Academy Press, Washington, DC.

Nelson, L.R., Bulun, S.E., 2001. Estrogen production and action. J. Am. Acad. Dermatol. 45, S116-S124.

Nohara, K., Zhang, Y., Waraich, R.S., Laque, A., Tiano, J.P., Tong J., et al., 2011. Early-life exposure to testosterone programs the hypothalamic melanocortin system. Endocrinology 152, 1661-1669.

Nowak, K.W., Kaczmarek, P., Mackowiak, P., Ziolkowska, A., Albertin, G., Ginda, W.J., et al., 2002. Rat thyroid gland expresses the long form of leptin receptors, and leptin stimulates the function of the gland in euthyroid non-fasted animals. Int J. Mol. Med. 9, 31-34.

Ogden, C.L., Carroll, M.D., Curtin, L.R., McDowell, M.A., Tabak, C.J., Flegal, K.M., 2006. Prevalence of overweight and obesity in the United States, 1999-2004. JAMA 295, 1549-1555.

Paxinos, G., Watson, C., 2005. The Rat Brain in Stereotaxic Coordinates, fifth ed. Elsevier Academic Press, New York. 
Pfaffl, M.W., 2001. A new mathematical model for relative quantification in real-time RT-PCR. Nucleic Acids Res. 29, e45.

Ribeiro, D.L., Pinto, M.E., Rafacho, A., Bosqueiro, J.R., Maeda, S.Y., Anselmo-Franci, J.A., et al., 2012. High-fat diet obesity associated with insulin resistance increases cell proliferation, estrogen receptor, and PI3K proteins in rat ventral prostate. J. Androl. 33, 854-865.

Rivera, P., Perez-Martin, M., Pavon, F.J., Serrano, A., Crespillo, A., Cifuentes, M., et al., 2013. Pharmacological administration of the isoflavone daidzein enhances cell proliferation and reduces high fat diet-induced apoptosis and gliosis in the rat hippocampus. PLoS ONE 8, e64750.

Ruhlen, R.L., Howdeshell, K.L., Mao, J., Taylor, J.A., Bronson, F.H., Newbold, R.R., et al., 2008. Low phytoestrogen levels in feed increase fetal serum estradiol resulting in the "fetal estrogenization syndrome" and obesity in CD-1 mice. Environ. Health Perspect. 116, 322-328.

Schwartz, M.W., Woods, S.C., Porte, D., Jr., Seeley, R.J., Baskin, D.G., 2000. Central nervous system control of food intake. Nature 404, 661671.

Setchell, K.D., Brown, N.M., Lydeking-Olsen, E., 2002. The clinical importance of the metabolite equol-a clue to the effectiveness of soy and its isoflavones. J. Nutr. 132, 3577-3584.

Simpson, E.R., 2003. Sources of estrogen and their importance. J. Steroid Biochem. Mol. Biol. 86, 225-230.
Titolo, D., Cai, F., Belsham, D.D., 2006. Coordinate regulation of neuropeptide Y and agouti-related peptide gene expression by estrogen depends on the ratio of estrogen receptor (ER) alpha to ERbeta in clonal hypothalamic neurons. Mol. Endocrinol. 20, 2080-2092.

Tsuruta, F., Sunayama, J., Mori, Y., Hattori, S., Shimizu, S., Tsujimoto, Y., et al., 2004. JNK promotes Bax translocation to mitochondria through phosphorylation of 14-3-3 proteins. EMBO J. 23, 1889-1899.

Valassi, E., Scacchi, M., Cavagnini, F., 2008. Neuroendocrine control of food intake. Nutr. Metab. Cardiovasc. Dis. 18, 158-168.

Vom Saal, F.S., Nagel, S.C., Coe, B.L., Angle, B.M., Taylor, J.A., 2012. The estrogenic endocrine disrupting chemical bisphenol A (BPA) and obesity. Mol. Cell. Endocrinol. 354, 74-84.

Wade, G.N., 1972. Gonadal hormones and behavioral regulation of body weight. Physiol. Behav. 8, 523-534.

Wang, Y.Y., Lin, S.Y., Chuang, Y.H., Chen, C.J., Tung, K.C., Sheu, W.H., 2011. Adipose proinflammatory cytokine expression through sympathetic system is associated with hyperglycemia and insulin resistance in a rat ischemic stroke model. Am. J. Physiol. Endocrinol. Metab. 300, E155-E163.

Younes-Rapozo, V., Moura, E.G., Manhaes, A.C., Pinheiro, C.R., Santos-Silva, A.P., de Oliveira, E., et al., 2013. Maternal nicotine exposure during lactation alters hypothalamic neuropeptides expression in the adult rat progeny. Food Chem. Toxicol. 58, 158-168. 